\title{
Polyploid formation in cotton is not accompanied by rapid genomic changes
}

\author{
B. Liu, C.L. Brubaker, G. Mergeai, R.C. Cronn, and J.F. Wendel
}

\begin{abstract}
Recent work has demonstrated that allopolyploid speciation in plants may be associated with non-Mendelian genomic changes in the early generations following polyploid synthesis. To address the question of whether rapid genomic changes also occur in allopolyploid cotton (Gossypium) species, amplified fragment length polymorphism (AFLP) analysis was performed to evaluate nine sets of newly synthesized allotetraploid and allohexaploid plants, their parents, and the selfed progeny from colchicine-doubled synthetics. Using both methylation-sensitive and methylationinsensitive enzymes, the extent of fragment additivity in newly combined genomes was ascertained for a total of approximately 22000 genomic loci. Fragment additivity was observed in nearly all cases, with the few exceptions most likely reflecting parental heterozygosity or experimental error. In addition, genomic Southern analysis on six sets of synthetic allopolyploids probed with five retrotransposons also revealed complete additivity. Because no alterations were observed using methylation-sensitive isoschizomers, epigenetic changes following polyploid synthesis were also minimal. These indications of genomic additivity and epigenetic stasis during allopolyploid formation provide a contrast to recent evidence from several model plant allopolyploids, most notably wheat and Brassica, where rapid and unexplained genomic changes have been reported. In addition, the data contrast with evidence from repetitive DNAs in Gossypium, some of which are subject to non-Mendelian molecular evolutionary phenomena in extant polyploids. These contrasts indicate polyploid speciation in plants is accompanied by a diverse array of molecular evolutionary phenomena, which will vary among both genomic constituents and taxa.
\end{abstract}

Key words: polyploidy, genome evolution, cotton, Gossypium, amplified fragment length polymorphism (AFLP).

Résumé : De récents travaux ont démontré que la spéciation via l'allopolyploïdisation chez les plantes s'accompagne parfois de changements génomiques non-mendéliens au cours des premières générations. Afin de déterminer si des changements génomiques rapides surviennent chez des espèces allopolyploïdes du cotonnier (Gossypium), une analyse AFLP (polymorphisme de longueur des fragments amplifiés) a été faite pour évaluer neuf jeux d'hybrides synthétiques allotétraploïdes ou allohexaploïdes, leurs parents et la progéniture obtenue par autofécondation suite au doublement chromosomique induit par la colchicine. À l'aide d'enzymes sensibles ou insensibles à la méthylation, le degré d'additivité des fragments a été évalué chez les génomes nouvellement combinés pour environ 22000 locus génomiques. L'additivité des fragments a été observée dans presque tous les cas et les quelques rares exceptions reflétaient vraisemblablement une hétérozygotie parentale ou une erreur expérimentale. De plus, des analyses Southern sur six jeux d'allopolyploïdes examinés à l'aide de sondes constituées de rétrotransposons ont également révélé une complète additivité. Comme aucune altération n'a été observée à l'aide des isoschizomères sensibles à la méthylation, les changements épigénétiques découlant de la synthèse des polyploïdes sont également peu nombreux. Ces évidences d'additivité génomique et de stabilité épigénétique lors de l'allopolyploïdisation contrastent avec les résultats récents chez plusieurs espèces modèles végétales, notamment le blé et Brassica. Chez ces dernières, des changements rapides et inexpliqués ont été rapportés. De plus, les données présentées contrastent avec celles obtenues avec des ADN répétés chez le Gossypium dont certains sont sujets à des phénomènes d'évolution moléculaire non-mendélienne chez les polyploïdes existants. Ces différences montrent que la spéciation via allopolyploïdisation chez les plantes s'accompagne de divers phénomènes évolutifs moléculaires, lesquels peuvent varier parmi les composantes génomiques et les taxons.

Mots clés : polyploïdie, évolution génomique, cotonnier, Gossypium, AFLP.

[Traduit par la Rédaction]

Received October 10, 2000. Accepted January 24, 2001. Published on the NRC Research Press Web site April 17, 2001.

Corresponding Editor: R.J. Kemble.

B. Liu, R.C. Cronn, and J.F. Wendel. ${ }^{1}$ Department of Botany, Iowa State University, Ames, IA 50011, U.S.A.

C.L. Brubaker. CSIRO Plant Industry, Centre for Plant Biodiversity Research, GPO Box 1600, Canberra, ACT 2601, Australia. G. Mergeai. Department of Tropical Crop Husbandry, Gembloux Agricultural University, B-5030 Gembloux, Belgium.

${ }^{1}$ Corresponding author (e-mail: jfw@iastate.edu). 


\section{Introduction}

The merger of two divergent genomes through allopolyploidization is a prominent means by which new lineages of plant species originate (Leitch and Bennett 1997; Soltis and Soltis 1999). Although the percentage of plant species that have experienced relatively recent episodes of genome doubling may be as high as 70\% (Masterson 1994), relatively little is known about the genetic and functional consequences of uniting two divergent genetic systems into a common nucleus in only one of the two parental cytoplasms (Wendel 2000). A critical period in the process is during and immediately after allopolyploid formation, when two distinct genomes are first brought into contact, thereby requiring a diverse array of genic, genomic, and physiological accommodations. Relatively little is known about the nature and scope of these interactions, but recent studies in several model plant systems have shown that allopolyploid formation may be associated with rapid and extensive genomic changes (Feldman et al. 1997; Liu et al. 1998a, 1998b; Song et al. 1995; Wendel et al. 1995). In Brassica (Song et al. 1995) and Triticum (Feldman et al. 1997; Liu et al. 1998a, $1998 b$ ), for example, allopolyploid formation has been associated with an unexplained appearance of novel genomic fragments in Southern blots, less than full additivity of parental genomes, and methylation changes. In allopolyploid Gossypium, duplicated ribosomal DNAs have been subjected to interlocus concerted evolution (Wendel et al. 1995) and many repetitive DNAs have spread beyond their genome of origin to the other resident genome following polyploid formation (Hanson et al. 1998, 1999; Zhao et al. 1998). These indications of novel process following allopolyploidization provide insight into the dynamic nature of nascent polyploids and have been suggested to be essential for the initial stabilization and establishment of the polyploid lineages. Alternatively, the changes observed may be selectively inconsequential.

One of the best-characterized examples of allopolyploid speciation occurs in the cotton genus (Gossypium). The approximately 40 diploid Gossypium species (Fryxell 1979, 1992; Percival et al. 1999) are divided into eight genome groups, designated as A-G and K (Endrizzi et al. 1985; Stewart 1995), and are variously distributed in the warm, arid to semiarid tropics and subtropics in Australia, AfricaArabia, and the Americas. Five natural polyploid Gossypium species are recognized (Percival et al. 1999; Wendel 1995; Wendel et al. 1999), of which all are allotetraploids bearing A and D genomes (viz. AADD; $2 n=4 x=52$ ). These species originated following hybridization between an African or Asian diploid species (genome AA; $2 n=26$ ), as female (Small and Wendel 1999; Wendel 1989), with a diploid American pollen donor (genome DD; $2 n=26$ ). Molecular data suggest that the allopolyploid Gossypium lineage arose about 1-2 million years ago, with divergence of the two progenitor diploid genomes occurring 4-8 million years earlier (Seelanan et al. 1997; Wendel and Albert 1992).

Recent investigations into the evolution of duplicated sequences in naturally occurring allopolyploid cotton have yielded contradictory results for repetitive and low-copy sequences. Whereas repetitive sequences, such as rDNA and retrotransposons, exhibited concerted or nonindependent evolution subsequent to polyploidization (Hanson et al.
1998, 1999; Zhao et al. 1998), phylogenetic analysis of duplicated low- and single-copy sequences showed that homoeologs exhibit complete additivity and independent evolution (Cronn et al. 1999; Small and Wendel 2000). To further address the issue of genome evolution in allopolyploid cotton, and particularly to investigate whether the aforementioned phenomena (rapid genomic changes) also occurred in this plant system, we undertook the present study. We were particularly interested in characterizing the early stages in allopolyploid formation (0-2 generations following colchicine doubling), as this period appears to be associated with unexplained genomic alterations in allopolyploid Triticum and Brassica (see, however, Axelsson et al. 2000). Hence, we studied newly synthesized allopolyploid progenies representing a variety of genome combinations. To efficiently examine a large number of nuclear loci in these progenies, we employed multi-fluorophore amplified fragment length polymorphism (AFLP) fingerprinting. This procedure provides thorough genome coverage, as demonstrated by mapping studies in Zea (Vuylsteke et al. 1999), Glycine (Young et al. 1999), and Gossypium (C.L. Brubaker, unpublished data). Here, we were able to evaluate predicted genomic additivity for over 2000 genomic loci in each synthetic progeny set. We also probed Southern blots carrying digested genomic DNAs from a subset of these polyploids and their parents with five representative retrotransposons isolated from cotton. In contrast with previous studies on other model polyploid plants, we found no evidence for either structural genomic changes or de novo DNA methylation modifications in any of the nine sets of cotton polyploids studied. We discuss possible reasons for the differential response to polyploidization in various plant systems and the implications for polyploid genome evolution.

\section{Materials and methods}

\section{Plant material}

To generate the synthetic progenies used in this study, parental plants, including both diploids and natural allopolyploids, were grown in greenhouse environments in either Australia (first five progenies of Table 1, termed Hyb synthetics) or Belgium (final four progenies of Table 1, termed G synthetics). In total, eight synthetic hexaploids and one tetraploid progeny were used in this study. Included in the eight synthetic allohexaploids are combinations of the naturally occurring allotetraploid Gossypium hirsutum (genome AADD) with representatives of six different diploid genome groups (B-G; Table 1). For five of the nine synthetic allopolyploids, the initial amphiploid $\left(\mathrm{C}_{0}\right)$ was selfed for one or two generations, in which case the resulting plants (designated as $\mathrm{C}_{1}$ and $\mathrm{C}_{2}$, respectively) were also included in the study.

$\mathrm{G}$ hybrids were synthesized either by J. Wouters (G350) in the Belgian Congo before 1960 or by R. Maréchal (G371, G390, G368) in Gembloux from 1973 to 1974, using Congolese cultivated varieties C2 (G107) and NC8 (G173) and wild species originating from the Iguala Research Institute, Mexico (Maréchal 1983). For all these hybrids, the genetic integrity of the initial amphidiploids $\left(\mathrm{C}_{0}\right)$ was maintained by grafting vegetative branches on G. hirsutum plantlets every 4-5 years. These plants were selfed for one or two generations $\left(\mathrm{C}_{1}, \mathrm{C}_{2}\right)$ to produce the genotypes used in the current paper.

The Hyb allopolyploids were generated as described in Brubaker et al. (1999a). In brief, emasculated flowers were pollinated on the day of anthesis between 08:00 and 11:00. Emasculations were performed the previous afternoon between 16:00 and 
18:00. A drop of $0.144 \mathrm{mM}(50 \mathrm{mg} / \mathrm{L}) \mathrm{GA}_{3}$ was applied to the floral cup at the time of emasculation and at the time of pollination to reduce premature fruit abscission. $\mathrm{G}$ allopolyploids were obtained as the Hyb allopolyploids but without application of growth regulators to the floral cup at the time of emasculation. The $F_{1}$ hybrids were grown to reproductive maturity prior to treatment with colchicine. Morphological comparisons and pollen sterility confirmed that all the plants were true intergenomic hybrids rather than accidental selfs.

To double the chromosome complement of the Hyb $F_{1}$ hybrids, mature plants were trimmed of all side branches and leaves. Colchicine was applied approximately 1 week later as the lateral axillary buds showed evidence of expansion. Plants to be treated were starved of water for $24 \mathrm{~h}$ before the end of the primary axis was cut to expose fresh tissue. A plastic pipette tip ( 1 or $5 \mathrm{~mL}$ ) was attached to the end of the primary axis with parafilm to create a reservoir. The reservoir was filled with $0.5 \%$ or $1 \% \mathrm{w} / \mathrm{v}$ colchicine to create a colchicine gradient down the stem. After $24 \mathrm{~h}$, the reservoir was removed. Successful treatments produced chimeric plants with sterile segments (with the original chromosome complement) and fertile amphiploid segments. To produce the $\mathrm{G}$ allohexaploids from sterile triploid $\mathrm{F}_{1}$ plants, a $0.15 \%$ colchicine aqueous solution was applied for $24 \mathrm{~h}$ with cotton wool on the terminal meristem of young plants just after cotyledon expansion. During this treatment, cotton plantlets were kept at room temperature in a water-saturated atmosphere to avoid water evaporation from the cotton wool; this procedure was necessary to prevent concentrating the colchicine, which would burn the terminal meristem. Fertile segments were easily identified by the larger flowers that produced fertile pollen, and ultimately by the production of viable seed. Chimeric plants were redesignated as $\mathrm{C}_{0}$ individuals, indicating that they had not undergone meiosis as an amphiploid. $\mathrm{C}_{1}$ seed were collected from fertile segments.

\section{Multi-fluorophore AFLP analysis}

Genomic DNA was isolated from young expanding leaves of individual plants of the parental lines, synthetic allopolyploids, and subsequent generations (where available) using the Nucleon Plant DNA isolation and purification kit (Amersham Corp., Piscataway, N.J.). Care was taken to use leaves at the same developmental stage from all plants.

To explore the genomic composition of the synthetics relative to their parents, we used two types of AFLP analysis, i.e., standard (Vos et al. 1995) and methylation-sensitive (Reyna-Lopez et al. 1997; Xiong et al. 1999). Standard AFLP analysis was carried out essentially according to the protocol of the $\mathrm{AFLP}^{\mathrm{TM}}$ Plant Mapping kit of PE/Applied Biosystems (Foster City, Calif.), with slight modifications (M. Gitzendanner and the Soltis lab, personal communication). Briefly, $800 \mathrm{ng}$ of genomic DNA was digested with 1 $\mathrm{U}$ of $M s e \mathrm{I}$ and $6 \mathrm{U}$ of EcoRI (or PstI) and simultaneously ligated to $50 \mathrm{pmol}$ of $M s e \mathrm{I}$ adaptors (I + II pre-annealed) and $5 \mathrm{pmol}$ of EcoRI (or PstI) adaptors (I + II pre-annealed) with 0.06 U T4 DNA ligase in $1 \times \mathrm{T} 4$ ligase buffer plus $50 \mathrm{mM} \mathrm{NaCl}$ and $50 \mathrm{ng} \mathrm{BSA} / \mathrm{L}$, in a total volume of $25 \mu \mathrm{L}$. The reaction was performed at $37^{\circ} \mathrm{C}$ for $3 \mathrm{~h}$. The restriction-ligation samples were diluted with $175 \mu \mathrm{L}$ $\mathrm{H}_{2} \mathrm{O}$ prior to preselective polymerase chain reaction (PCR) amplification. The latter was carried out by using a single selective base at the $3^{\prime}$ end of each of the MseI and EcoRI (or PstI) primers (Table 2). Each PCR reaction contained $0.3 \mu \mathrm{M}[\mathrm{MseI}+1], 0.3 \mu \mathrm{M}$ [EcoRI (or PstI) + 1], $1.0 \mathrm{U}$ of Taq DNA polymerase (GIBCOBRL, Grand Island, N.Y.), $0.2 \mathrm{mM}$ of each dNTP, and $4 \mu \mathrm{L}$ of diluted restriction-ligation sample, in $1 \times$ PCR reaction buffer (GIBCO-BRL) in a total volume of $20 \mu \mathrm{L}$. The amplification profile was one cycle of $72^{\circ} \mathrm{C}$ for $2 \mathrm{~min}$, followed by 20 cycles of $94^{\circ} \mathrm{C}$ for $30 \mathrm{~s}, 56^{\circ} \mathrm{C}$ for $30 \mathrm{~s}$, and $72^{\circ} \mathrm{C}$ for $2 \mathrm{~min}$, and one final extension at $60^{\circ} \mathrm{C}$ for $30 \mathrm{~min}$. Ten microlitres of this PCR reaction was electrophoresed through $1.5 \%$ agarose gels and stained with ethidium bromide to verify preselective amplification, which when successful results in a relatively even smear of amplification products in the size range of $100-1500 \mathrm{bp}$. The remaining $10 \mu \mathrm{L}$ of PCR product was diluted with $150-200 \mu \mathrm{L}$ of $\mathrm{H}_{2} \mathrm{O}$ prior to selective amplification.

Fluorometric methods were used for detection of AFLP fragments. These methods recently have been shown to provide higher resolution than conventional radio-detection techniques (Schwarz et al. 2000). For multi-fluorophore fragment analysis (multiplexing), EcoRI (or PstI) primers were labeled with either 6-carboxyfluorescein (6-FAM) or 4,7,2',7'-tetrachloro-6-carboxyfluorescein (TET), and the MseI primer was unlabeled. Selective amplification was carried out using $M s e \mathrm{I}$ and EcoRI (or PstI) primers, each with three additional bases at their $3^{\prime}$ end (Table 2). Each multiplexing PCR was carried out using $2.5 \mu \mathrm{L}$ of the diluted preselective amplifications, $0.1 \mu \mathrm{M}$ each of two [EcoRI +3$]$ primers labeled with 6FAM and TET, $0.15 \mu \mathrm{M}$ [MseI +3 primer $], 0.5 \mathrm{U}$ of Taq DNA polymerase, $0.2 \mathrm{mM}$ of each $\mathrm{dNTP}$, and $1 \times$ PCR reaction buffer in a $10-\mu \mathrm{L}$ volume. The amplification protocol was 1 cycle of $94^{\circ} \mathrm{C}$ for $2 \mathrm{~min}, 1 \mathrm{cycle}$ of $94^{\circ} \mathrm{C}$ for $30 \mathrm{~s}, 65^{\circ} \mathrm{C}$ for $30 \mathrm{~s}$, and $72^{\circ} \mathrm{C}$ for $2 \mathrm{~min}$, followed by nine cycles of a $1.0^{\circ} \mathrm{C}$ decrease in annealing temperature per cycle, followed by 35 cycles of $94^{\circ} \mathrm{C}$ for $30 \mathrm{~min}$, $56^{\circ} \mathrm{C}$ for $30 \mathrm{~s}$, and $72^{\circ} \mathrm{C}$ for $2 \mathrm{~min}$, and a final extension at $60^{\circ} \mathrm{C}$ for $30 \mathrm{~min}$. PCR reactions were also conducted using only one $E c o$ RI +3 primer at a time to confirm the additivity expected from multiplexing.

Methylation-sensitive AFLP analysis was performed using protocols identical to those described earlier for standard AFLP analysis, except that genomic DNA was digested with HpaII + EcoRI or $M s p \mathrm{I}+E c o$ RI. HpaII and MspI are isoschizomers that recognize the same tetranucleotide sequence 5 -CCGG but with different sensitivities to methylation at the inner cytosines. Care was taken to ensure complete digestion by adding an excess amount of restriction enzyme (10 U/reaction) and by using longer than standard incubation times (overnight). Preselective amplification was accomplished with $[E c o R I+1]$ and $[H p a I I / M s p I+0]$ primers. Selective amplification was performed using [EcoRI +3$]$ and $[H p a \mathrm{II} / \mathrm{MspI}+4]$ primers (Table 2). Reaction components and conditions are exactly as described earlier.

Amplification products were electrophoretically separated using automated sequencing gels on an ABI Prism ${ }^{\text {TM }} 373$ DNA sequencer, at the DNA synthesis and sequencing center at Iowa State University. AFLP images were analyzed with Genescan ${ }^{\text {TM }}$ analysis software, version 2.0.2, and Genotyper ${ }^{\mathrm{TM}}$, version 2.0 (PE/Applied Biosystems), and by visual inspection.

\section{Southern blot analysis}

Genomic DNAs of six sets of cotton synthetic polyploids (Table 1) were digested to completion with either HindIII or a combination of [HindIII $+H p a \mathrm{II}]$ or [HindIII $+M s p \mathrm{I}]$. Restriction fragments were transferred onto Hybond $\mathrm{N}+$ nylon membranes by alkaline transfer. One clone corresponding to a portion of the integrase region of a gypsy-like retroelement (R.C. Cronn, unpublished data) and four clones corresponding to a portion of the reverse transcriptase gene from cotton copia-like retroelements were used as probes. The latter four were selected to sample as widely as possible within the diverse population of cotton copia-like elements, based on the phylogenetic analysis of VanderWiel et al. (1993). Probe labeling, hybridization, post-hybridization washing, and autoradiography were standard.

\section{Results}

The AFLP methods employed permitted the evaluation of a far larger number of independent molecular markers than has conventionally been possible by Southern hybridizationbased means. The number of bands detected was approxi- 
Table 1. Synthetic Gossypium amphiploids surveyed for non-Mendelian genomic alterations.

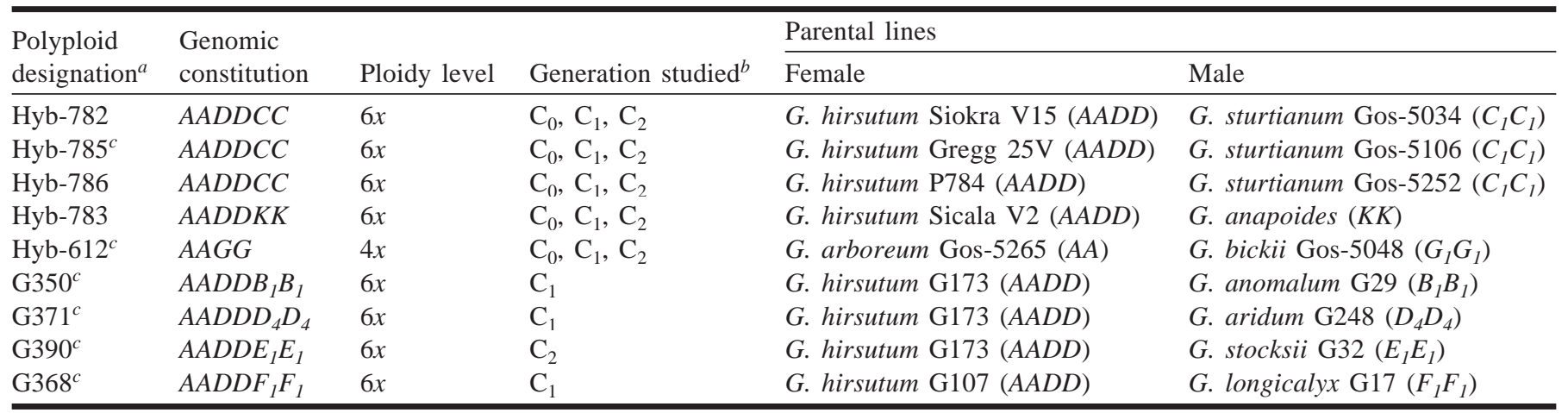

${ }^{a}$ Accessions predicated by Hyb were synthesized as described in Brubaker et al. (1999a); synthesis of accessions predicated by G are described in Maréchal (1983).

${ }^{b}$ Subscripts designate the generation since chromosome doubling and correlate with the number of meioses as an amphiploid.

${ }^{c}$ Used for Southern blot analysis.

mately the same using either PstI/MseI- or EcoRI/MseIbased AFLP methods, although the size range scored typically was slightly higher ( $\sim 50 \mathrm{bp})$ for the former. Similarly, the number of parental fragments was equivalent using EcoRI paired with either HpaII or its isoschizomer MspI. As detailed later in the paper, the percentage of amplicons that distinguished the two parents of each synthetic allopolyploid was similar among the different AFLP methods.

\section{Standard AFLP analysis reveals genomic stasis in synthetic cotton allopolyploids}

The total number of parental fragments scored using eight pairs of primers for each of the plant-enzyme combinations is summarized in Table 3. Among plant combinations, the number of parental fragments varies from 518 to 815 for $M s e \mathrm{I}+E c o$ RI digests and from 420 to 963 for $M s e \mathrm{I}+P s t \mathrm{I}$ digests. Totaled across all nine progenies, 12400 bands were scored in the parents, of which 6941 were unique to either one parent or the other $(56.0 \%)$. Hence, nearly 7000 genetic loci were directly tested for transmission to the synthetic allopolyploid and in some cases its selfed descendants. Among plant combinations, the minimum number of diagnostic fragments tested for transmission to the synthetic allopolyploid was 641 (Hyb-785) and the maximum was 953 (G390).

To address the issue of whether genomic changes occurred during or subsequent to allopolyploidization, presence-absence of each of the unique parental fragments was visually scored in the amphiploids. This inspection revealed that $(i)$ loss of parental fragments was rare, as evidenced by the fact that of the 18 plant-enzyme combinations, eight showed complete fragment additivity, six showed a single fragment loss, and four showed between two and five fragments losses (Table 3); (ii) novel fragments did not appear in any of the plant-enzyme combinations (Table 3); (iii) in five of the nine amphiploids, where individuals from successive selfed generations $\left(\mathrm{C}_{0}-\mathrm{C}_{2}\right)$ were surveyed, no variation in the fingerprint patterns was detected between generations (Table 3); and (iv) almost all fragment loss observed was unidirectional, i.e., from the diploid wild species, which likely contain some heterozygous loci. Because AFLPs behave as dominant markers, heterozygosity in the parental lines cannot be diagnosed without progeny tests. Taken to- gether, we conclude that the rare fragment losses in the amphiploids more likely reflected inheritance of null alleles at loci for which the parental plant was heterozygous rather than de novo genomic changes following allopolyploidization.

\section{Methylation-sensitive AFLP analysis indicates absence of de novo DNA methylation changes in synthetic cotton polyploids}

The total number of parental fragments scored using eight primer pairs for each of plant-enzyme (EcoRI + HpaII or EcoRI + MspI) combinations is summarized in Table 4. Among plant combinations, the number of parental fragments varies from 429 to 665 for EcoRI + HpaII digests and from 427 to 620 for EcoRI + MspI digests (Table 4). The level of parental polymorphism ranged from 49.9 to $70.8 \%$, similar to that detected using the standard AFLP described earlier. Totaled across all nine progenies, 9729 bands were scored in the parents, of which 5769 were unique to either one parent or the other $(59.3 \%)$. This latter number represents the total number of genetic loci that were directly tested for transmission to the synthetic allopolyploid and in some cases its selfed descendants. Among plant combinations, the minimum number of diagnostic fragments tested for transmission to the synthetic allopolyploid was 527 (Hyb-782) and the maximum was 827 (G390). The number of amplicons detected using EcoRI + HpaII digests was similar to the number detected in EcoRI + MspI digests; differences for these two isoschizomers reflect the presence of cytosine methylation at internal Cs of CCGG sites.

Comparison of the parental fingerprints with those of the corresponding allopolyploid, as well as between the two enzyme digests for a given allopolyploid, revealed that $(i) 10$ of the 18 plant-enzyme combinations yielded complete additivity, (ii) identical patterns were invariably detected in both of the corresponding two enzyme digests of the eight plant-enzyme combinations that showed fragment loss, (iii) no intergeneration variability was detected for a given allopolyploid, and (iv) nearly all fragment loss was from the wild species. Taken together, we conclude that de novo cytosine methylation changes at CCGG sites (a prominent cytosine methylation site in plants) did not occur to an appreciable degree following allopolyploidization, and the 
Table 2. AFLP adapters and primers (primer combinations) and RFLP probes used in this study.

\begin{tabular}{|c|c|}
\hline & Sequence or description \\
\hline \multicolumn{2}{|l|}{ Adapters } \\
\hline MseI-adapterI & 5'-GACGATGAGTCCTGAG \\
\hline MseI-adapterII & 5'-TACTCAGGACTCAT \\
\hline EcoRI-adapterI & 5'-CTCGTAGACTGCGTACC \\
\hline EcoRI-adapterII & 5'AATTGGTACGCAGTC \\
\hline Pst I-adapterI & 5'-CTCGTAGACTGCGTACATGCA \\
\hline HpaII/MspI-adapterII & 5'-CGAGCAGGACTCATGA \\
\hline \multicolumn{2}{|l|}{ Preselective primers } \\
\hline$M s e \mathrm{I}+\mathrm{C}$ & 5'GACGATGAGTCCTGAGTAAC \\
\hline$E c o R I+A$ & 5'-GACTGCGTACCAATTCA \\
\hline$P s t \mathrm{I}+\mathrm{A}$ & 5'-GACTGCGTACATGCAGA \\
\hline$H p a \mathrm{II} / M s p \mathrm{I}+0$ & 5'ATCATGAGTCCTGCTCGG \\
\hline$E c o \mathrm{RI}+\mathrm{AAC}$ & $E c o \mathrm{RI}+\mathrm{A}+\mathrm{AC}$ (combined with both $M s e \mathrm{I}+3$ primers $)$ \\
\hline$E c o \mathrm{RI}+\mathrm{ACA}$ & $E c o \mathrm{RI}+\mathrm{A}+\mathrm{CA}$ (combined with both $M s e \mathrm{I}+3$ primers $)$ \\
\hline$E c o R I+A C G$ & $E c o R I+A+C G$ (combined with both $M s e I+3$ primers $)$ \\
\hline$E c o R I+A G C$ & $E c o \mathrm{RI}+\mathrm{A}+\mathrm{GC}$ (combined with both $M s e \mathrm{I}+3$ primers $)$ \\
\hline Pst $\mathrm{I}+\mathrm{AAC}$ & Pst $\mathrm{I}+\mathrm{A}+\mathrm{AC}$ (combined with both $M s e \mathrm{I}+3$ primers $)$ \\
\hline Pst I + ACA & Pst $\mathrm{I}+\mathrm{A}+\mathrm{CA}$ (combined with both $M s e \mathrm{I}+3$ primers $)$ \\
\hline Pst I + ACG & Pst $\mathrm{I}+\mathrm{A}+\mathrm{CG}$ (combined with both $M s e \mathrm{I}+3$ primers $)$ \\
\hline$P s t \mathrm{I}+\mathrm{AGC}$ & Pst $\mathrm{I}+\mathrm{A}+\mathrm{GC}$ (combined with both $M s e \mathrm{I}+3$ primers $)$ \\
\hline$H p a \mathrm{II} / M s p \mathrm{I}+\mathrm{TCAC}$ & $H p a \mathrm{II} / M s p \mathrm{I}+0+\mathrm{TCAC}$ (combined with the four EcoRI +3 primers) \\
\hline$H p a \mathrm{II} / M s p \mathrm{I}+\mathrm{TCAA}$ & $H p a \mathrm{II} / M s p \mathrm{I}+0+$ TCAA (combined with the four EcoRI +3 primers) \\
\hline \multicolumn{2}{|r|}{ 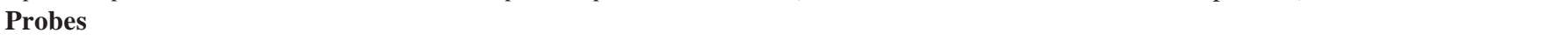 } \\
\hline Cel A3 & 750-bp fragment of integrase from a gypsy-like element from $G$. herbaceum \\
\hline
\end{tabular}

few fragment losses most likely reflect parental heterozygosity, as indicated in the previous section.

\section{Southern blot analysis detects no sequence-epigenetic changes or activity of retroelements in synthetic cotton polyploids \\ For each of five radiolabeled cotton retrotransposons, no} new bands were detected in Southern blot analyses of the synthetic allopolyploids, relative to the fragment profiles observed in the parents. This complete additivity was observed for all six sets of synthetic allopolyploids evaluated (Table 1). By comparing hybridization profiles using isoschizomers that differ in methylation sensitivity, it also was evident that there was no dramatic change in methylation status of the retroelements in the synthetic allopolyploids (data not shown). We conclude that allopolyploid formation has not been associated with sudden and large increases in retroelement activity or changes in retroelement methylation status.

\section{Discussion}

A surprising degree of genomic nonadditivity recently has been reported for both natural and artificial allopolyploid plants (Feldman et al. 1997; Hanson et al. 1998, 1999; Liu et al. 1998a, 1998b; Song et al. 1995; Volkov et al. 1999; Wendel et al. 1995; Zhao et al. 1998). In Brassica (Song et al. 1995), restriction fragment length polymorphism (RFLP) analysis of synthetic allopolyploid progenies revealed the presence of novel restriction fragments in genomic Southerns, as well as disappearance of parental fragments (see, however, Axelsson et al. 2000). Using similar techniques, the fate of specific sequences has been studied in a variety of different natural and synthetic allopolyploid Triticum and Aegilops (Feldman et al. 1997; Liu et al. $1998 a, 1998 b)$. Although most low-copy probes representing coding sequences have been shown to behave conventionally, in that the expected additive patterns are recovered, some low-copy, noncoding sequences appear to be preferentially eliminated in one of the two genomes of allotetraploid wheat and two of the three genomes of allohexaploid wheat. Moreover, synthetic allopolyploids exhibited Southern hybridization profiles that are similar to natural and established allopolyploid wheats, suggesting that polyploidy-induced sequence elimination is repeatable and is somehow mediated by the presence of specific sequences. Collectively, the data on Brassica and Triticum show that in some allopolyploids there are rapid genetic and genomic interactions during the 


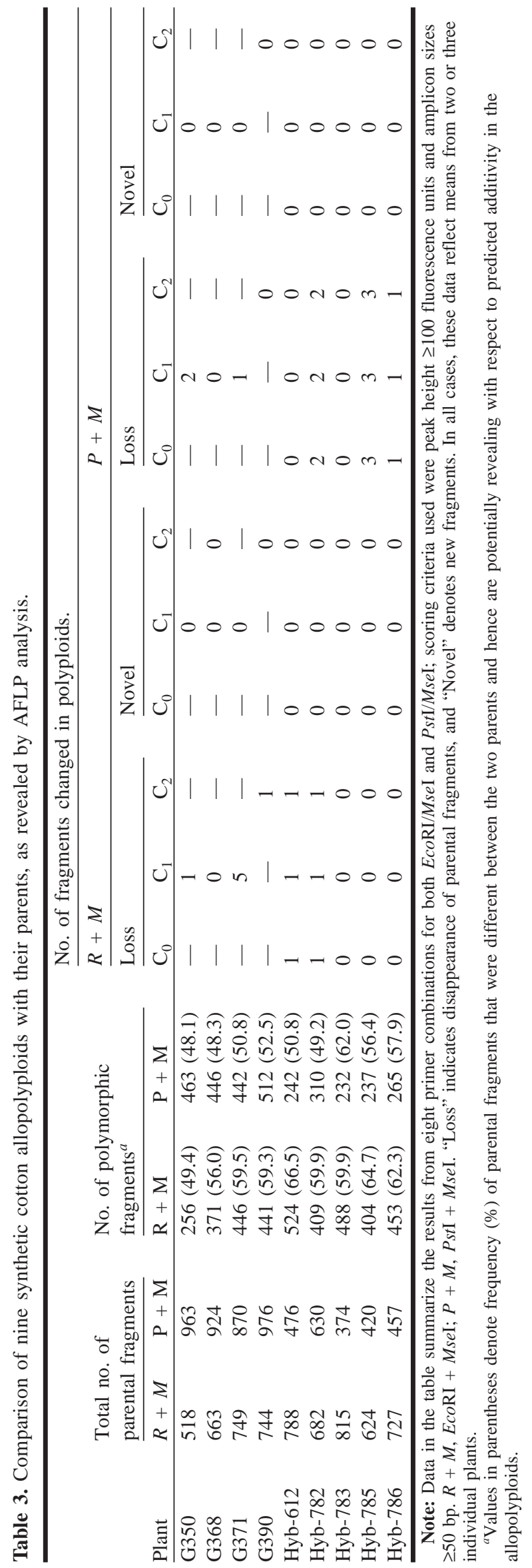

initial stages of formation, which include non-Mendelian genetic mechanisms for which satisfactory mechanistic explanations are lacking. Neither the generality of these observations nor their functional significance is known, although it has been suggested that rapid genome evolution contributes to initial stabilization of nascent allopolyploids and long-term evolutionary success (Feldman et al. 1997; Leitch and Bennett 1997; Soltis and Soltis 1995, 1999; Wendel 2000). This suggestion is bolstered by recent demonstrations of novel phenotypic diversity among newly synthesized allopolyploids in Brassica (Schranz and Osborn 2000) and Arabidopsis (Comai et al. 2000).

Gossypium provides one of the textbook examples of speciation via allopolyploidy. The organismal history suggested by classic cytogenetic analyses has been repeatedly confirmed by recent molecular phylogenetic analyses, which also have served to illuminate the timing of diploid divergence events and allopolyploidization (Percival et al. 1999; Wendel 1995; Wendel et al. 1999). Several different aspects of naturally occurring allopolyploid Gossypium species have been studied, including the degree of chromosomal synteny and genic colinearity relative to diploid progenitors (Brubaker et al. 1999b), patterns of homoeologous sequence evolution at duplicated single-copy (Cronn et al. 1999; Small and Wendel 2000) and repetitive sequences (Wendel et al. 1995), and the invasion of repetitive elements into one subgenome from the other following allopolyploidization (Hanson et al. 1998, 1999; Zhao et al. 1998). It has not been known, however, whether synthetic allopolyploid progenies in Gossypium, and by extension other allopolyploids, are subject to the same non-Mendelian genomic phenomena as exhibited by early generations in Brassica and Triticum.

To address whether rapid genome change is likely a hallmark of all nascent plant allopolyploids, or a characteristic of only certain plant groups, we compared the genomic compositions of nine sets of newly synthesized allopolyploid cotton plants to that of their parents using a total of 12710 parental fragments that could be directly tested for transmission to the progenies. A common feature of the genome constitution of all but one (the tetraploid) of these synthetic allopolyploids is that they contain a naturally occurring allotetraploid (Gossypium hirsutum) as the maternal parent. Our hypothesis was that the diverse nature of the paternal parents would not only promise a high probability of detecting and quantifying genomic changes but also permit insight into some of the possible factors influencing the extent of genomic interaction (e.g., genetic distance between genomes and genome size). Contrary to our expectation and in a contrast with the data from Brassica and wheat, our AFLP survey demonstrated near-complete genomic stasis in all nine sets of plants studied. Moreover, de novo DNA methylation changes that were detected in both Brassica and wheat, and implicated as one responsible mechanism for novel fragments, were not found by methylation-sensitive AFLP analysis in any of the nine sets of plants. Thus, we conclude that rapid genomic change is not associated with allopolyploid formation in cotton. One difference between this study and the Brassica or wheat experiments is that the Gossypium allopolyploids were grown to a maximum of two generations since chromosome doubling $\left(\mathrm{C}_{2}\right)$, whereas fifth- to sixthgeneration Brassica and wheat plants were studied. Given 
the near-complete genomic stasis across generations in the Gossypium progenies, however, it is difficult to imagine that drastic changes would suddenly occur in the subsequent several generations. Furthermore, in the case of the Brassica study, although the number of changes reflected the cumulative effect of five or six generations, some changes were observed in the initial generations.

Our AFLP results are consistent with those obtained from recent phylogenetic analyses of sequence variation at approximately 20 low-copy genomic loci in naturally occurring allopolyploid cotton and its extant two diploid progenitors (Cronn et al. 1999; Small and Wendel 2000). Recovery of the expected phylogenetic topology for each of these gene trees demonstrates that since allopolyploidization about 1-2 million years ago, most low-copy nuclear loci have not interacted, through gene conversion or some other mechanism. Similar results have been obtained for $5 \mathrm{~S}$ ribosomal sequences (Cronn et al. 1996). Contrary to this pattern of independence and stasis, analyses of some repetitive sequences and several characterized retrotransposons have shown that there has been "invasion" of alternative subgenomes since allopolyploid formation (Hanson et al. 1998, 1999; Zhao et al. 1998). In addition, homoeologous 18 S-26S rDNA arrays in natural allopolyploid cotton have interacted to such an extent that only a single sequence type remains, the other having been "over-written" by some concerted evolutionary process (Wendel et al. 1995). Collectively these data indicate that most low-copy sequences evolve independently in natural allopolyploid cotton and probably are not subject to rapid genome changes, at least at the sequence level. Responses to allopolyploidization have been heterogeneous, however, as shown by the intergenomic interactions exhibited by repetitive sequences, including retrotransposons and rDNAs.

Given the apparent contradiction between the AFLP results, which presumably sampled a large number of highly repeated genomic regions and those having less redundancy, and previous work which shows intergenomic spread of repetitive DNAs, it was of interest to directly evaluate whether specific repetitive sequences were subject to alterations in the synthetic progenies we examined. To accomplish this we selected representatives of five characterized retrotransposon families as probes for Southern blot analysis, some of which are known to have exhibited intergenomic retrotranspositions in natural allopolyploid cotton (Hanson et al. 1998, 1999; Zhao et al. 1998). As with the AFLP analysis, complete additivity was found in all plant-probe combinations. Thus, there was no evidence for de novo structural or epigenetic changes for sequences homologous to the probes per se, nor was there apparent novel retroactivation in the hybrids (contra Comai 2000; Liu and Wendel 2000; O'Neill et al. 1998, 1999). We cannot exclude the possibility of these phenomena, however, as our techniques included only some classes of retroelements, and low levels of novel retrotransposition would go undetected against the background smears observed in Southern blot analysis using both methylationsensitive and methylation-insensitive enzymes. Moreover, the previous demonstration of intergenomic spread of retrotransposons in natural Gossypium allopolyploids constitutes irrefutable evidence that on a longer time scale there is intergenomic crosstalk.

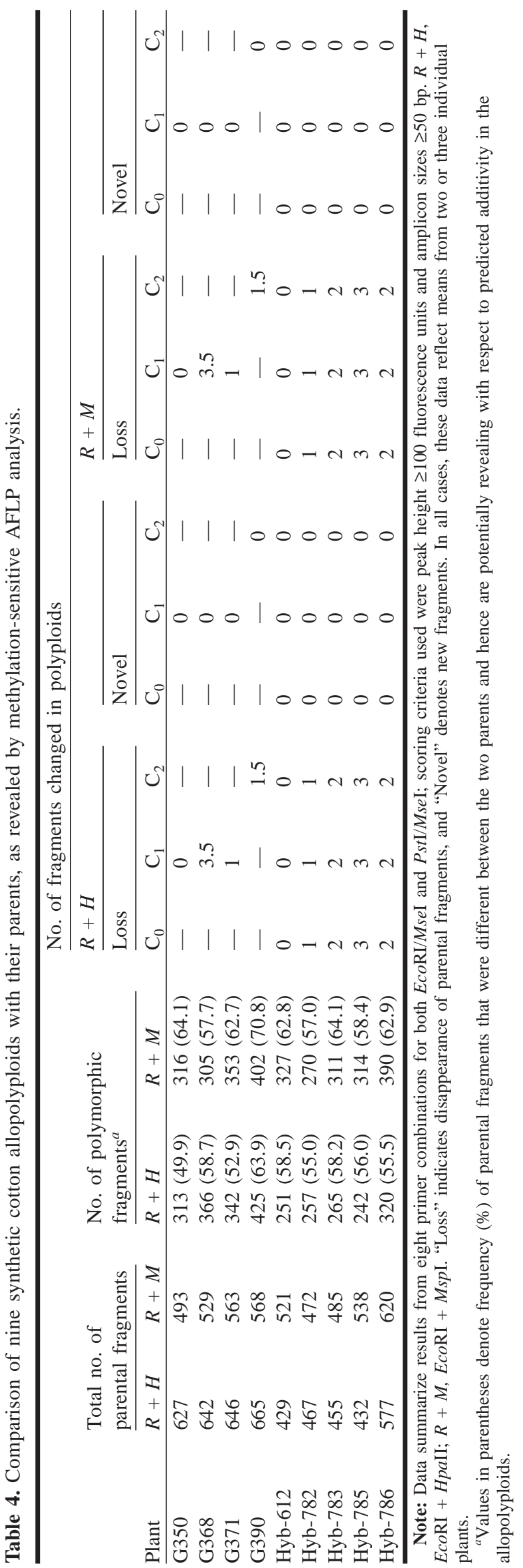

(C) 2001 NRC Canada 
The foregoing discussion demonstrates that, relative to Brassica and Triticum, nascent Gossypium allopolyploids are genomically quiescent. The realization that the immediate genomic consequences of allopolyploidization may differ among plant groups leads to questions regarding the features that promote or suppress genomic interactions and rapid genomic change. One obvious potential determinant of the extent of genome interaction expected in a nascent allopolyploid is degree of divergence among parental chromosome sets, either structurally or at the primary sequence level. Indeed, our study was designed to incorporate as broad a range as possible in this respect (reviewed in Endrizzi et al. 1985). We note that included in the eight allohexaploids involving G. hirsutum (AADD) as the maternal parent (Table 1) are paternal genomes of varying genetic distances to the two (A and D) maternal genomes. For example, G371 has two different D genomes in the allohexaploid nucleus, and hence a high frequency of tetravalents at meiosis, whereas in Hyb783 the paternal parent has a genome size (Stewart 1995) that is larger than that of the A and D genomes combined. Thus, if degree of either gross or sequence homology is an important determinant of genomic interaction in the initial allopolyploid nucleus, we would have expected to detect this with our experimental design.

The absence of a relationship between genetic or cytogenetic distance and non-Mendelian genomic aberrations indicates that in Gossypium and perhaps other plant polyploids multivalent formation or other manifestations of structural differentiation are not necessarily causally connected to rapid genomic change as revealed through Southern hybridization or AFLP analysis. This suggestion is additionally supported by the contrast between Brassica, where there is a high frequency of multivalents in newly synthesized allopolyploids (Song et al. 1995), and Triticum, where there is almost exclusive bivalent formation ( $\mathrm{M}$. Feldman, personal communication). In both cases, rapid genomic changes occur.

If, as our data suggest, the degree of cytostructural similarity and the degree of sequence similarity are not the most relevant variables accounting for the range of genomic aberrations observed in nascent plant allopolyploids, what factors are? One possibility is that specific DNA sequences and (or) proteins involved in nonhomologous chromosome interactions are responding differently in the various allopolyploid systems. For example, mutations leading to inactivation of mismatch-repair genes in mammals can cause various genomic instabilities that may lead to carcinogenesis (Arnheim and Shibata 1997). Comai (2000) recently speculated that mismatch-repair systems in plants might be compromised when divergent genomes are brought together. He suggests that high levels of genomic mismatch might titrate available pools of mismatch-repair enzymes, and thus nonhomologous interactions would go uncorrected and be revealed as genomic instability. Perhaps these and other proteins involved mediate the level of nonhomologous chromosome interaction, and do so variably among different plant allopolyploids. Similarly, some epigenetic systems such as DNA methylation-demethylation (Finnegan et al. 1998) may mediate genomic interactions through effects on ectopic recombination (Robertson and Wolffe 2000; Yoder et al. 1997), and also may be related to activation of quiescent mobile elements (Matzke and Matzke 1998; Matzke et al. 1999; O'Neill et al. 1998; Robertson and Wolffe 2000); to the extent that these mechanisms differ among allopolyploids, we might therefore expect variation in levels of genomic instability.

It seems important to distinguish between genomic and genetic changes that might accompany the earliest stages of allopolyploid formation from longer term evolutionary change. As evidenced by previous studies of natural (i.e., older) allopolyploid Gossypium, genomic alterations do occur, may be non-Mendelian in nature, and may differentially affect various components of the genome. Whether these latter phenomena occur gradually over evolutionary time or saltationally is an open question.

Polyploid formation in cotton is known to have created novel genetic opportunities for response to artificial selection. This has been shown by genetic mapping analysis of QTLs affecting the quality and quantity of fibers (Jiang et al. 1998) and by comparative morphological analysis of fiber development in wild and cultivated species (Applequist et al. 2001). These studies offer the perspective that, even though nascent allopolyploids are genomically relatively stable and duplicated single-copy genes largely evolve independently of one another at the sequence level, allopolyploid formation may be associated with "expression novelty." In this respect the recent report by Comai et al. (2000) is especially noteworthy. They demonstrated both gene silencing and novel transcript formation in newly synthesized Arabidopsis polyploids. Our data further suggest that these kinds of modified expression patterns may develop without physical changes or intergenomic interactions at the DNA sequence level. The initial genomic stasis and long-term sequence additivity in allopolyploid cotton do not necessarily rule out other novel paradigms, either genetic or epigenetic, rendered possible by bringing two or more divergent genomes together into a common nucleus and cytoplasm. Thus, our present results do not necessarily contradict the emerging notion that polyploid plant genomes are unexpectedly dynamic; rather, they point to the differences among plant systems, highlight several distinctions regarding timing and nature of evolutionary change, and add a layer of complexity to our understanding of rapid and long-term evolution in polyploid plant genomes.

\section{Acknowledgements}

We thank M. Gitzendanner and the Soltis lab for advice with AFLP methods. The contribution of the third author was supported by the Belgian Fonds de la recherche fondamentale collective (FRFC). This work was supported by the United States - Israel Binational Science Foundation.

\section{References}

Applequist, W.L., Cronn, R.C., and Wendel, J.F. 2001. Comparative development of fiber in wild and cultivated cotton. Evol. Dev. 3: 1-15.

Arnheim, N., and Shibata, D. 1997. DNA mismatch repair in mammals: role in disease and meiosis. Curr. Opin. Genet. Dev. 7: 364-370. 
Axelsson, T., Bowman, C.M., Sharpe, A.G., Lydiate, D.J., and Lagercrantz, U. 2000. Amphidiploid Brassica juncea contains conserved progenitor genomes. Genome, 43: 679-688.

Brubaker, C.L., Brown, A.H.D., Stewart, J.M., Kilby, M.J., and Grace, J.P. 1999a. Production of fertile hybrid germplasm with diploid Australian Gossypium species for cotton improvement. Euphytica, 108: 199-213.

Brubaker, C.L., Paterson, A.H., and Wendel, J.F. 1999b. Comparative genetic mapping of allotetraploid cotton and its diploid progenitors. Genome, 42: 184-203.

Comai, L. 2000. Genetic and epigenetic interactions in allopolyploid plants. Plant Mol. Biol. 43: 387-399.

Comai, L., Tyagi, A.P., Winter, K., Holmes-Davis, R., Reynolds, S.H., Stevens, Y., and Byers, B. 2000. Phenotypic instability and rapid gene silencing in newly formed Arabidopsis allotetraploids. Plant Cell, 12: 1551-1567.

Cronn, R.C., Zhao, X., Paterson, A.H., and Wendel, J.F. 1996. Polymorphism and concerted evolution in a tandemly repeated gene family: 5S ribosomal DNA in diploid and allopolyploid cottons. J. Mol. Evol. 42: 685-705.

Cronn, R., Small, R.L., and Wendel, J.F. 1999. Duplicated genes evolve independently following polyploid formation in cotton. Proc. Natl. Acad. Sci. U.S.A., 96: 14406 - 14411.

Endrizzi, J.E., Turcotte, E.L., and Kohel, R.J. 1985. Genetics, cytogenetics, and evolution of Gossypium. Adv. Genet. 23: 271-375.

Feldman, M., Liu, B., Segal, G., Abbo, S., Levy, A.A., and Vega, J.M. 1997. Rapid elimination of low-copy DNA sequences in polyploid wheat: a possible mechanism for differentiation of homoeologous chromosomes. Genetics, 147: 1381-1387.

Finnegan, E.J., Genger, R.K., Peacock, W.J., and Dennis, E.S. 1998. DNA methylation in plants. Annu. Rev. Plant Physiol. Plant Mol. Biol. 49: 223-247.

Fryxell, P.A. 1979. The natural history of the cotton tribe. Texas A\&M University Press, College Station, Tex.

Fryxell, P.A. 1992. A revised taxonomic interpretation of Gossypium L. (Malvaceae). Rheedea, 2: 108-165.

Hanson, R.E., Zhao, X.-P., Islam-Faridi, M.N., Paterson, A.H., Zwick, M.S., Crane, C.F., McKnight, T.D., Stelly, D.M., and Price, H.J. 1998. Evolution of interspersed repetitive elements in Gossypium (Malvaceae). Am. J. Bot. 85: 1364-1368.

Hanson, R.E., Islam-Faridi, M.N., Crane, C.F., Zwick, M.S., Czeschin, D.G., Wendel, J.F., Mcknight, T.D., Price, H.J., and Stelly, D.M. 1999. Ty1-copia-retrotransposon behavior in a polyploid cotton. Chromosome Res. 8: 73-76.

Jiang, C., Wright, R., El-Zik, K., and Paterson, A.H. 1998. Polyploid formation created unique avenues for response to selection in Gossypium (cotton). Proc. Natl. Acad. Sci. U.S.A., 95: 4419-4424.

Leitch, I.J., and Bennett, M.D. 1997. Polyploidy in angiosperms. Trends Plant Sci. 2: 470-476.

Liu, B., and Wendel, J.F. 2000. Retroelement activation followed by rapid repression in interspecific hybrid plants. Genome, $\mathbf{4 3}$ : 874-880.

Liu, B., Vega, J.M., and Feldman, M. 1998a. Rapid genomic changes in newly synthesized amphiploids of Triticum and Aegilops. II. Changes in low-copy coding DNA sequences. Genome, 41: 535-542.

Liu, B., Vega, J.M., Segal, G., Abbo, S., Rodova, M., and Feldman, M. 1998b. Rapid genomic changes in newly synthesized amphiploids of Triticum and Aegilops. I. Changes in low-copy non-coding DNA sequences. Genome, 41: 272-277.

Maréchal, R. 1983. Une collection d'hybrides interspécifiques du genre Gossypium. Coton Fibres Trop. 38: 240-246.
Masterson, J. 1994. Stomatal size in fossil plants: evidence for polyploidy in majority of angiosperms. Science (Washington, D.C.), 264: 421-424.

Matzke, M.A., and Matzke, A.J.M. 1998. Gene silencing in plants: relevance for genome evolution and the acquisition of genomic methylation patterns. In Epigenetics: Novartis Foundation Symposium 214. Edited by D.J. Chadwick and A.P. Wolffe. Wiley, Chichester, U.K. pp. 168-186.

Matzke, M.A., Scheid, O.M., and Matzke, A.J.M. 1999. Rapid structural and epigenetic changes in polyploid and aneuploid genomes. Bioessays, 21: 761-767.

O’Neill, R.J.W., O'Neill, M.J., and Graves, J.A.M. 1998. Undermethylation associated with retroelement activation and chromosome remodelling in an interspecific mammalian hybrid. Nature (London), 393: 68-72.

O’Neill, R.J.W., O’Neill, M.J., and Graves, J.A.M. 1999. Reply to Reomer et al.: Global methylation in eutherian hybrids. Nature (London), 401: 132.

Percival, A.E., Stewart, J.M., and Wendel, J.F. 1999. Taxonomy and germplasm resources. In Cotton: origin, history, technology and production. Editor by C.W. Smith and J.T. Cothren. John Wiley, New York. pp. 33-63.

Reyna-Lopez, G.E., Simpson, J., and Ruiz-Herrera, J. 1997. Differences in DNA methylation patterns are detectable during the dimorphic transition of fungi by amplification of restriction polymorphisms. Mol. Gen. Genet. 253: 703-710.

Robertson, K.D., and Wolffe, A.P. 2000. DNA methylation in health and disease. Nat. Rev. Genet. 1: 11-19.

Schranz, M.E., and Osborn, T.C. 2000. Novel flowering time variation in the resynthesized polyploid Brassica napus. J. Hered. 91: 242-246.

Schwarz, G., Herz, M., Huang, X.Q., Michalek, W., Jahoor, A., Wenzel, G., and Mohler, V. 2000. Application of fluorescencebased semi-automated AFLP analysis in barley and wheat. Theor. Appl. Genet. 100: 545-551.

Seelanan, T., Schnabel, A., and Wendel, J.F. 1997. Congruence and consensus in the cotton tribe. Syst. Bot. 22: 259-290.

Small, R.L., and Wendel, J.F. 1999. The mitochondrial genome of allotetraploid cotton (Gossypium L.). J. Hered. 90: 251-253.

Small, R.L., and Wendel, J.F. 2000. Copy number lability and evolutionary dynamics of the Adh gene family in diploid and tetraploid cotton (Gossypium). Genetics, 155: 1913-1926.

Soltis, D.E., and Soltis, P.S. 1995. The dynamic nature of polyploid genomes. Proc. Natl. Acad. Sci. U.S.A., 92: 8089-8091.

Soltis, D.E., and Soltis, P.S. 1999. Polyploidy: origins of species and genome evolution. Trends Ecol. Evol. 9: 348-352.

Song, K., Lu, P., Tang, K., and Osborn, T.C. 1995. Rapid genome change in synthetic polyploids of Brassica and its implications for polyploid evolution. Proc. Natl. Acad. Sci. U.S.A., 92: 7719-7723

Stewart, J.M. 1995. Potential for crop improvement with exotic germplasm and genetic engineering. In Challenging the Future: Proceedings of the World Cotton Research Conference. Edited by G.A. Constable and N.W. Forrester. CSIRO, Melbourne, Australia. pp. 313-327.

VanderWiel, P.S., Voytas, D.F., and Wendel, J.F. 1993. Copia-like retrotransposable element evolution in diploid and polyploid cotton (Gossypium L.). J. Mol. Evol. 36: 429-447.

Volkov, R.A., Borisjuk, N.V., Panchuk, I.I., Schweizer, D., and Hemleben, V. 1999. Elimination and rearrangement of parental rDNA in the allotetraploid Nicotiana tabacum. Mol. Biol. Evol. 16: $311-320$.

Vos, P., Hogers, R., Bleeker, M., Reijans, M., van de Lee, T., Hornes, M., Frijters, A., Pot, J., Peleman, J., Kuiper, M., and 
Zabeau, M. 1995. AFLP: a new technique for DNA fingerprinting. Nucleic Acids Res. 23: 4407-4414.

Vuylsteke, R., Mank, R., Antonise, R., Bastiaans, E., Senior, M.L., Stuber, C.W., Melchinger, A.E., Lubberstedt, T., Xia, X.C., Stam, P., Zabeau, M., and Küiper, M. 1999. Two high-density AFLP linkage maps of Zea mays L.: analysis of distribution of AFLP markers. Theor. Appl. Genet. 99: 921-935.

Wendel, J.F. 1989. New World tetraploid cottons contain Old World cytoplasm. Proc. Natl. Acad. Sci. U.S.A., 86: 4132-4136.

Wendel, J.F. 1995. Cotton. In Evolution of crop plants. Edited by N. Simmonds and J. Smartt. Longman, London. pp. 358-366.

Wendel, J.F. 2000. Genome evolution in polyploids. Plant Mol. Biol. 42: 225-249.

Wendel, J.F., and Albert, V.A. 1992. Phylogenetics of the cotton genus (Gossypium L.): character-state weighted parsimony analysis of chloroplast DNA restriction site data and its systematic and biogeographic implications. Syst. Bot. 17: 115-143.

Wendel, J.F., Schnabel, A., and Seelanan, T. 1995. Bidirectional interlocus concerted evolution following allopolyploid speciation in cotton (Gossypium). Proc. Natl. Acad. Sci. U.S.A., 92: 280284.
Wendel, J.F., Small, R.L., Cronn, R.C., and Brubaker, C.L. 1999 Genes, jeans, and genomes: reconstructing the history of cotton. In Plant Evolution in Man-made Habitats: Proceedings of the 7th International Symposium of the International Organization of Plant Biosystematists. Edited by L.W.D. van Raamsdonk and J.C.M. den Nijs. Hugo de Vries Laboratory, Amsterdam. pp. 133-161.

Xiong, L.Z., Xu, C.G., Saghai-Maroof, M.A., and Zhang, Q. 1999. Patterns of cytosine methylation in an elite rice hybrid and its parental lines, detected by a methylation-sensitive amplification polymorphism technique. Mol. Gen. Genet. 261: 439-446.

Yoder, J.A., Walsh, C.P., and Bestor, T.H. 1997. Cytosine methylation and the ecology of intragenomic parasites. Trends Genet. 13: $335-340$.

Young, W.P., Schupp, J.M., and Keim, P. 1999. DNA methylation and AFLP marker distribution in the soybean genome. Theor. Appl. Genet. 99: 785-790.

Zhao, X.-P., Si, Y., Hanson, R.E., Crane, C.F., Price, H.J., Stelly, D.M., Wendel, J.F., and Paterson, A.H. 1998. Dispersed repetitive DNA has spread to new genomes since polyploid formation in cotton. Genome Res. 8: 479-492. 